\title{
The effect of total quality management on marketing educational services in Saudi universities
}

\author{
Nabil Mohemmed Al-Hazmi ${ }^{a^{*}}$
}

${ }^{a}$ Associate Professor of Marketing-Department of Marketing, College of Business Administration, Prince Sattam bin Abdulaziz University-Kingdom of Saudi Arabia

${ }^{b}$ Associate Professor of Marketing-College of Administrative Sciences- Taiz University-Yemen

\section{H R O N I C L E}

Article history:

Received: January 28, 2020

Received in revised format:

January 302020

Accepted: February 29, 2020

Available online:

March 2, 2020

Keywords:

$T Q M$

Marketing

Education

Service

\section{Introduction}

The success of many academic institutions depends on their capability to work and planning systematically \& effectively for its various activities and the development of new concepts such as globalization, total quality management (TQM) and related international quality specifications and high-quality regulation of all activities (Sallis, 2014). There is no longer opportunity for failed organizations to survive and there is no place except for the powerful people who are capable of coping up and interacting with the changes of the times (Alahmmed, 2018). The marketing activity has become important for the work of universities of all kinds and its importance increases in marketing educational services for universities to confront marketing problems (Al-Hazmia, 2020a). The most important of which is the complexity of the concept of education service and the multiplicity of methods presented to it as well as the multiplicity of parties receiving the service and their difference in terms of desires and motivations and how the university deals with them in order to enhance the level of satisfaction about its services and thus continuing to deal with them (Al-Hazmia, 2020b). Also, among the problems facing the marketing of educational services is the lack of tangibility of these services and the spread of educational services to give more than one city (AL-Hazmi \& Alkhateeb, 2020). Also, the marketing of educational services suffers from a shortage of staff who is able to perform the work professionally due to the recent concept of marketing for educational services in the Kingdom (Alsaid, 2015, 2018). Through this, marketing has become a vital role in educational institutions in terms of supporting its survival and continuity (Althamoor, 2017). All these changes and developments have led university institutions to adopt the marketing concept, especially with the characteristics of educational services in addition to the development of new facts that confirm * Corresponding author.

E-mail address: alhazmi1976@gmail.com (N. M. Al-Hazmi)

(C) 2020 by the authors; licensee Growing Science, Canada doi: $10.5267 /$ j.msl.2020.3.002 
the importance of the customer, the quality of service and the way to deal with the public as important criteria in marketing the services of educational institutions in order to achieve a competitive advantage (Ghosha \& Takriti, 2017; Hatto \& Alhaj, 2017). It is required from the administration of educational institutions to searching for means and methods through which they can compete and obtain better results through the use of the characteristics of the educational service, its quality and the way it is presented as a new field of competition (Ksem, 2018; Retha, 2018). Thus, TQM has become one of the main functions in modern educational institutions in order to achieve its goals.

\section{Study Problem}

Most educational institutions seek to apply TQM, but this application is below the required level, resulting in neglecting the important and vital role of TQM in marketing for educational services which is the fundamental of this study. There is a TQM that controls all operations in the institution, especially those related to customer or customer service. This has led to the consumer's confidence in this institution and thus increased loyalty and belonging to it, because of its eagerness to provide the best services to it and very high quality, and save time, effort and money. AL-Hazmi and Alkhateeb (2020) determined various obstacles preventing the overall quality management in marketing tourism services in Saudi Arabia. The study found a number of key issues on applying overall quality management in marketing tourism services in Saudi Arabia. Al-Hazmi (2020b) investigated the main policies and procedures related to internal marketing. This study came to investigate the impact of TQM on marketing educational services in the Kingdom of Saudi Arabia.

\subsection{Study Importance}

The importance of this study stems from the fact that it highlights how to use TQM in marketing educational services.

\subsection{Study Objectives}

This study aims to identify the relationship between TQM and marketing and its impact on specifying the target customers and educational services provided to them.

\subsection{Study Hypotheses}

The study hypothesis is as follows:

There is a statistically significant effect at the significance level $(\alpha \leq 0.05)$ of TQM in the marketing of educational services at Prince Sattam bin Abdulaziz University. From this hypothesis, the following sub-hypotheses can be derived:

- There is a statistically significant effect at the significance level $(\alpha \leq 0.05)$ for the participation of workers in decisions in the marketing of educational services at Prince Sattam bin Abdulaziz University.

- There is a statistically significant effect at the significance level $(\alpha \leq 0.05)$ to take care of customer in marketing educational services at Prince Sattam bin Abdulaziz University.

- There is a statistically significant effect at the significance level $(\alpha \leq 0.05)$ for incentives and appreciation in the marketing of educational services at Prince Sattam bin Abdulaziz University

- There is a statistically significant effect at the significance level $(\alpha \leq 0.05)$ for continuous improvement in the marketing of educational services at Prince Sattam bin Abdulaziz University.

- There is a statistically significant effect at the significance level $(\alpha \leq 0.05)$ for teams working in marketing educational services at Prince Sattam bin Abdulaziz University.

\subsection{Study Methodology}

The study depended on the descriptive analytical approach, by referring to previous studies related to the subject of the study, in addition to using the analytical approach to try to test the hypotheses of the study, and reach its results, by depending on a special tool developed for the purposes of this study.

\subsection{Population \& Study Sample}

The study population consisted of employees at Prince Sattam bin Abdulaziz University. A random sample was chosen from the study community, which amounted to (200) individuals, including (100) employees (internal employees) and (100) external university customers. Fig. 1 shows the characteristics of workers at the university under study. As we can observe from the results, about half of the participants maintained some university degrees. Moreover, more than half of the population have had at least five years of job experience. While two-third of the participants were male. 


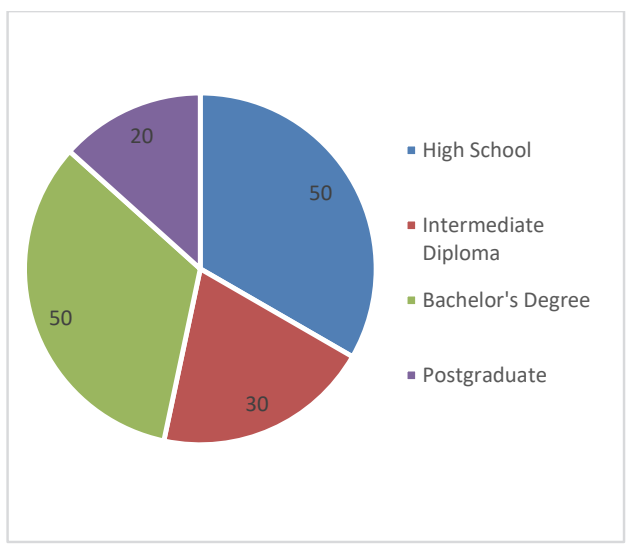

Educational background

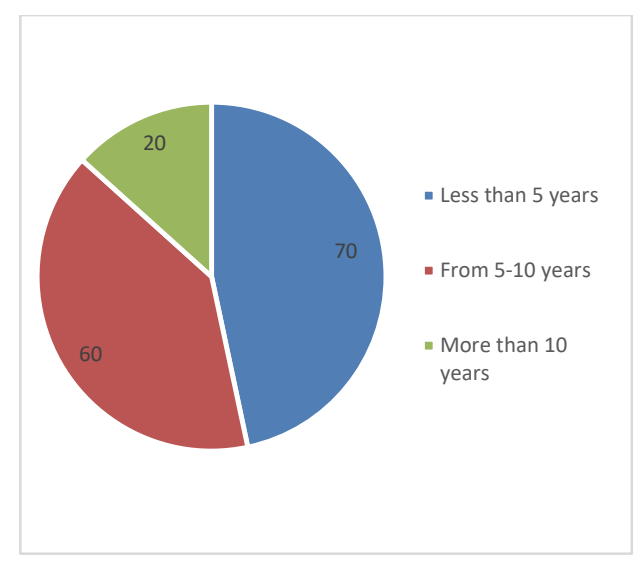

Job experience

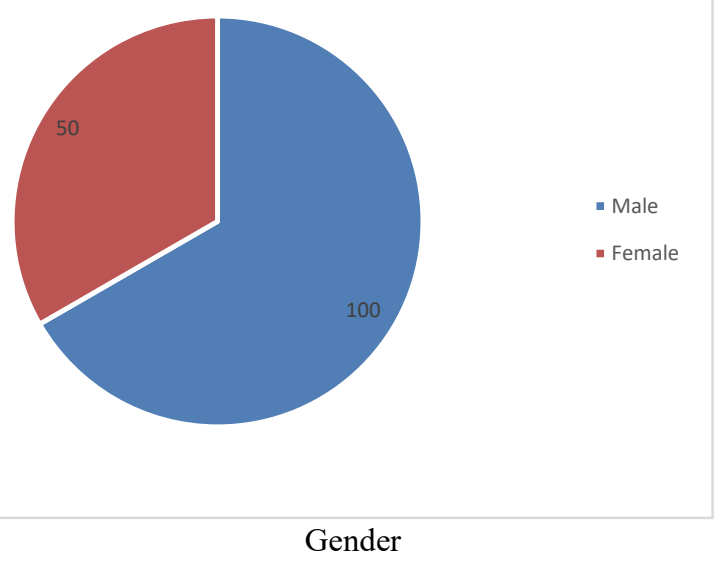

Fig. 1. Personal characteristics of the participants

\subsection{Study Tool}

In order to achieve the aims of the study, two questionnaire forms were designed as follows:

First: A Total Quality Management Questionnaire

A tool was developed to achieve the aims of the study by referring to previous studies related to Total Quality Management, and the study tool included two parts:

The first part includes the personal characteristics (gender, educational qualification, and experience), while the second part is devoted to measuring the principles of Total Quality Management, and it includes five principles (continuous improvement, customer care, incentives \& appreciation, work teams, and the participation of workers in decision-making). The development of the study tool was based on the Likert Scale, and the weights of its paragraphs were calculated as follows: (Strongly agree) and represent (5 grades), and (Agree) and represent (4 degrees), (neutral) and represent ( 3 degrees), and (not approved) and represent (2 degrees), (strongly disagree) and represent (1 degree).

Second: A questionnaire for marketing educational services.

A tool was developed to achieve the purposes of the study by referring to the theoretical literature related to the marketing of educational services. The questionnaire consisted of (12) items, and the study tool was developed on the Likert Scale. Weights of its paragraphs were calculated as follows: (Strongly agreed) It represents (5 degrees), (OK) and represents (4 degrees), (neutral) and represents (3 degrees), and (not approved) and represents (2 degrees), (strongly disagree) and represents (1 degree).

\subsection{Study Tool Validity and Reliability}

The study tool was presented to a number of specialists in the field of business administration at Prince Sattam bin Abdulaziz University, King Faisal University and Ab University, to find out the appropriateness and validity of the questionnaire paragraphs linguistically, and their belonging to the dimension within which the arbitrators' observations and opinions were taken, and some paragraphs were rewritten in light of these notes (Ksem, 2018). The internal consistency coefficient of the study 
tool was extracted, the degree of respondents agreeing to the items of the study tool based on the Cronbachs' alpha equation, and the coefficient of stability was high as it reached (0.94), which is an acceptable stability ratio.

Table 1

Coefficient of internal consistency for each principle of Total Quality Management

\begin{tabular}{|c|c|c|}
\hline Paragraphs & The Principles of Total Quality Management & Alpha Cronbach Coefficient \\
\hline $1-5$ & Continuous Improvement & 0.83 \\
\hline $6-12$ & Customer Attention & 0.86 \\
\hline $13-17$ & Incentives and Appreciation & 0.90 \\
\hline $18-21$ & Work Teams & 0.88 \\
\hline $22-29$ & Participation of Workers in Decisions & 0.92 \\
\hline
\end{tabular}

\section{Literature Review}

There are no studies which address the topic of the effect of the quality of education services in Saudi universities on the marketing of these services, but there are studies which address the quality of education services or dealt with the marketing of educational services and there are a set of studies that address the impact of quality services on other sectors in marketing these services. Al-Hazmi study (2020) investigated the effect of internal marketing on the employees' satisfaction at Prince Sattam bin Abdulaziz University, stressed on the importance of internal marketing in achieving employees' satisfaction as well as achieving the quality of the service provided. While the study of Al-Hazmi and Al-Khatib (2019) emphasized the existence of a set of obstacles facing the application of TQM in the services sector.

From the above, we find that previous studies did not address the effect of TQM in marketing services at Prince Sattam bin Abdulaziz University, as this study is unique to that.

\section{Analysis of Study Variables}

Descriptive analysis was conducted for all study variables according to the responses of the study sample individuals on the paragraphs in the questionnaire. The arithmetic averages and standard deviations were calculated, and they were arranged in a descending order according to their relative importance according to the arithmetic value. Taking into consideration the scale used in the study, and based on that. The values of the arithmetic mean that the study reached, depended on a criterion if the arithmetic mean value of the paragraphs is greater than (3.5), then the level of the study sample individuals' estimation is high, but if the arithmetic value is $(2.5-3.49)$ the level for the mean is average. If the arithmetic mean (2.49) or less, then the level for the mean is low.

\section{First: an analysis of the principles of TQM.}

Mathematical averages and standard deviations were extracted from workers' perceptions of the principles of TQM, and Table 2 shows that.

\section{Table 2}

Arithmetic averages and standard deviations of employees' perceptions of the principles of total quality management are in descending order.

\begin{tabular}{cclccc}
\hline Rank & N. & The Principles of Total Quality Management & Mean & $\begin{array}{c}\text { Sd. Devo- } \\
\text { tion }\end{array}$ & Degree (Approval) * \\
\hline 1 & 1 & Continuous Improvement & 4.280 & .0510 & High \\
2 & 2 & Customer Attention & .4191 & .0590 & High \\
3 & 4 & Incentives and Appreciation & 3.001 & .0789 & Medium \\
4 & 3 & Work Teams & 1.898 & 0.981 & Medium \\
5 & 5 & Participation of Workers in Decisions & 1.785 & 0.969 & Medium \\
\hline Total & & 3.209 & 0.598 & Medium \\
\hline
\end{tabular}

* (1 - less than 2.8) weak, (2.8 - less than 3.6) medium, (3.6-5) high

It is noted from Table 3 that the general average for TQM reached (3.209) at an intermediate level. By analyzing the principles of TQM. It is clear that the principle of continuous improvement ranked first with an average score of $(4,280)$. Followed by the principle of caring for customers with an average score of $(4,191)$, followed by the principle of working teams with an average score of (3.001), followed by the principle of incentives and estimation with an average score of (1.898). In the last rank, the principle of employee participation in decisions came with an average mathematical average of (1.785). The perceptions of the study sample individuals for continuous improvement and customer interest were high. While their perceptions on the other principles were average. 
Table 3

Arithmetic averages and standard deviations of employees' perceptions for each of the principles of total quality management, in descending order

\begin{tabular}{|c|c|c|c|c|c|}
\hline Rank & No. & Paragraph & Mean & $\begin{array}{c}\text { Sd. } \\
\text { Devotion }\end{array}$ & Degree \\
\hline 1 & 1 & Quality includes all colleges and departments of the university. & 4.456 & 0.660 & High \\
\hline 2 & 4 & The customer service is constantly being developed and improved. & 4.443 & 0.652 & High \\
\hline 3 & 3 & Continuously developing and updating quality. & 4.345 & 0.598 & High \\
\hline 4 & 2 & The university is constantly developing its goals. & 4.298 & 0.579 & High \\
\hline \multicolumn{3}{|c|}{ Continuous improvement of the overall degree } & 4.012 & 0.542 & High \\
\hline 1 & 6 & The University continuously works to understand the needs, expectations and desires of customers. & 4.583 & 0.712 & High \\
\hline 2 & 5 & The University prioritizes customer complaints. & 4.489 & 0.669 & High \\
\hline 3 & 9 & The University collects total information about customer complaints. & 4.355 & 0.674 & High \\
\hline 4 & 8 & The University makes direct personal contacts with customers. & 4.303 & 0.602 & High \\
\hline 5 & 7 & The university conducts an annual survey of the level of customer's satisfaction. & 4.179 & 0.590 & High \\
\hline \multicolumn{3}{|c|}{ Customer interest is the overall degree } & 4.321 & 0.621 & High \\
\hline 1 & 13 & I am paid better and get moral incentives from the university than other universities. & 3.398 & 1.291 & Medium \\
\hline 2 & 11 & Overtime conditions are better or similar to those applied in other universities. & 3.385 & 1.271 & Medium \\
\hline 3 & 10 & I get a suitable wage compared to my colleagues. & 3.109 & 1.321 & Medium \\
\hline 4 & 12 & The payment is proportional to the level of work that he has accomplished. & 3.100 & 1.311 & Medium \\
\hline \multicolumn{3}{|c|}{ Incentives and appreciation is the overall degree } & 3.011 & 1.264 & Medium \\
\hline 1 & 15 & Workers in one department work as groups. & 3.499 & 1.041 & Medium \\
\hline 2 & 14 & The different departments of the university cooperate to help each other. & 3.319 & 1.020 & Medium \\
\hline 3 & 16 & The university promotes teamwork more than individual work. & 3.290 & 1.017 & Medium \\
\hline \multicolumn{3}{|c|}{ Team work is the overall degree } & 3.176 & 0.798 & Medium \\
\hline 1 & 18 & Workers are encouraged to apply their skills after training. & 3.432 & 1.201 & Medium \\
\hline 2 & 17 & The staff are obligated and concerned with the success of the university. & 3.242 & 0.998 & Medium \\
\hline 3 & 19 & The university encourages workers to make decisions to solve problems, which face them. & 3.103 & 0.976 & Medium \\
\hline 4 & 20 & The university involves workers in the decision-making process. & 2.106 & 0.2000 & Low \\
\hline \multicolumn{3}{|c|}{ Participation of workers in decisions is the overall degree } & 2.987 & 0.957 & Medium \\
\hline
\end{tabular}

*Prepared by Researcher.

It is noted from Table 3 that all paragraphs of continuous improvement and customer's care were high, while all paragraphs of incentives \& appreciation and work teams were medium, and finally paragraphs of employee participation in decisions were medium except for paragraph (20) is low.

\section{Second: Analysis of the Marketing of Educational Services.}

Mathematical averages and standard deviations for customer's perceptions of educational services marketing level were extracted, and summarized in Table 4.

\section{Table 4}

Arithmetic averages and standard deviations of customer perceptions of respondents to the level of marketing educational services arranged in descending order

\begin{tabular}{cclccc}
\hline Rank & $\begin{array}{c}\text { No. of } \\
\text { paragraph }\end{array}$ & \multicolumn{1}{c}{ Paragraph } & Mean & $\begin{array}{c}\text { Sd. } \\
\text { Devotion }\end{array}$ & $\begin{array}{c}\text { Level } \\
\text { Digh }\end{array}$ \\
\hline 1 & 6 & University employees have a good reputation in serving their clients. & 4.261 & 0.520 & High \\
2 & 4 & I think the university working hours are appropriate. & 4.182 & 0.693 & High \\
3 & 8 & I feel the staff can easily understand my order. & 4.129 & 0.714 & High \\
\hline 4 & 10 & Feeling the good reception of the customer at the university. & 4.123 & 0.723 & High \\
5 & 1 & The university uses advanced technologies. & 4.097 & 0.601 & High \\
6 & 3 & Staff respond to my inquiries quickly. & 4.056 & 0.697 & High \\
7 & 9 & University employees adapt the service to meet my request. & 3.991 & 0.674 & High \\
8 & 11 & The appearance of the university staff is decent. & 3.891 & 0.789 & High \\
9 & 2 & University employees are skilled in providing the service. & 3.760 & 0.801 & High \\
10 & 12 & The university's interior design is organized and integrated. & 3.603 & 0.896 & High \\
11 & 7 & You can depend on university employees. & 3.760 & 0.801 & High \\
12 & 5 & The university's facilities and buildings are attractive to customers. & 3.600 & 0.878 & High \\
\hline Total & & & $\mathbf{3 . 7 2 0}$ & $\mathbf{0 . 4 5 8}$ & High \\
\hline
\end{tabular}

It is noted from Table 4 that the level of marketing of educational services is high, with an arithmetic average of $(3,720)$, and all the paragraphs were high. Their arithmetic mean was higher than (3.5).

\section{Testing Study hypotheses}

The main hypothesis states that: There is a statistically significant effect on the significance level $(\alpha \leq 0.05)$ for TQM in the marketing of educational services. 
Table 5

Simple regression test results to test the effect of TQM on marketing educational services.

\begin{tabular}{lcccccc}
\hline Independent Variables & Beta & $\mathrm{t}$ (value) & $\mathrm{t}$ sig. & $\mathrm{R}^{2}$ & $\mathrm{f}($ value $)$ & $\mathrm{f}$ sig. \\
\hline Continuous Improvement & 0.034 & 0.132 & 0.766 & & & \\
Customer Attention & 0.144 & 1.102 & 0.378 & & & \multirow{2}{*}{$* 0.00$} \\
Incentives and Appreciation & 0.103 & 0.143 & 0.745 & 0.598 & \multirow{2}{*}{$* 4.433$} & \\
Work Teams & 0.354 & 2.798 & $* 0.024$ & & & \\
Participation of Workers in Decisions & 0.356 & 2.471 & $* 0.013$ & & & \\
\hline
\end{tabular}

* Significant correlation at the level of significance $(\alpha=0.05)$

Table 5 shows the stability of the validity of the main hypothesis model. The value of (f) (13.443) reached the level of significance $(0.00)$, which is the lowest level of significance $(\alpha=0.05)$, and it is also clear that TQM in this model explains the amount of (68). \%) Of the variance in the dependent variable is the marketing of educational services, which is a relatively high explanatory value, which indicates that there is a statistically significant effect of the independent variables on the dependent variable (marketing of banking services). It is also noted from the follow-up of the (Beta) coefficients and the test ( $t$ ) that the two independent variables (work teams, and the participation of workers in decisions) have an impact on the marketing of educational services, in terms of the high coefficient of (Beta) for him, as well as the values of (t) were statistically significant when Significance level $(\alpha=0.05)$. It also shows that the independent variables (continuous improvement, customer care, incentives \& appreciation) had no effect on the marketing of educational services, in terms of a decrease in the Beta coefficient for him, and the values of $(\mathrm{t})$ were not statistically significant at the level of significance $(\alpha=0.05)$. Based on these results, the study hypothesis is accepted (the alternative hypothesis) which states that, there is a statistically significant effect at the level of significance $(\alpha \leq 0.05)$ for TQM (work teams, and the participation of workers in decisions) in the marketing of educational services, rejects the study hypothesis and accepts the nihilistic hypothesis which states that there is no statistically significant effect at the level of significance $(\alpha \leq 0.05)$ of TQM (continuous improvement, customer care, incentives $\&$ appreciation) in the marketing of educational services.

The first sub-hypothesis states that: There is a statistically significant effect at the significance level $(\alpha \leq 0.05)$ of continuous improvement in the marketing of educational services.

Table 6

Results of testing the impact of continuous improvement in the marketing of educational services.

\begin{tabular}{llll}
\hline Beta & $\mathrm{t}($ value $)$ & $\mathrm{t}$ sig. & $\mathrm{R}^{2}$ \\
\hline 0.405 & 3.231 & $0.003 *$ & 0.165 \\
\hline * Statistically significant at the level of significance $(\alpha=0.05)$ & &
\end{tabular}

It is noted from Table 6 that the value of $(t)$ amounted to (3.231) with a probability value (0.003) which is less than the level of significance $(\alpha=0.05)$, which indicates a statistically significant effect of continuous improvement in the marketing of educational services, and this is enhanced by a high value (Beta), and the explanatory value was $17.6 \%$. Based on these results, it rejects the nihilistic hypothesis and accepts the alternative hypothesis (the study hypothesis) which states that there is a statistically significant effect at the level of significance $(\alpha \leq 0.05)$ on continuous improvement in the marketing of educational services.

The second sub-hypothesis states that, there was a statistically significant effect on the significance level $(\alpha \leq 0.05)$ of customer interest in the marketing of educational services.

Table 7

Results of testing the effect of customer interest on the marketing of educational services.

\begin{tabular}{llll}
\hline Beta & $\mathrm{t}($ value $)$ & $\mathrm{t}$ sig. & $\mathrm{R}^{2}$ \\
\hline 0.415 & 3.128 & $0.003 *$ & 0.160 \\
\hline * Statistically significant at the level of significance $(\alpha=0.05)$ & &
\end{tabular}

* Statistically significant at the level of significance $(\alpha=0.05)$

It is noted from Table 7 that the value of $(\mathrm{t})$ reached (3.128) with a probability value $(0.003)$ which is less than the level of significance $(\alpha=0.05)$, which indicates a statistically significant effect of customer interest on the marketing of educational services, and this is enhanced by the high value (Beta), the explanatory value was $16.9 \%$. Based on these results, it rejects the nihilistic hypothesis, and accepts the alternative hypothesis (the study hypothesis) which states that there is a statistically significant effect on the level of importance $(\alpha \leq 0.05)$ of customer interest in the marketing of educational services

The third sub-hypothesis states that, there is a statistically significant effect at the level of significance $(\alpha \leq 0.05)$ of incentives and appreciation in the marketing of educational services.

Table 8

Results of testing the effect of incentives and appreciation in marketing educational services

\begin{tabular}{lll}
\hline Beta & $\mathrm{t}($ value $)$ & $\mathrm{t}$ sig. \\
\hline 0.4990 & 4.512 & $0.002 *$ \\
\hline * Statistically significant at the level of significance $(\alpha=0.05)$ & 0.314
\end{tabular}

* Statistically significant at the level of significance $(\alpha=0.05)$ 
It is noted from Table 8 that the value of $(\mathrm{t})$ reached (4.512) with a probability value $(0.002)$ which is less than the level of significance $(\alpha=0.05)$, which indicates a statistically significant effect of incentives and appreciation in the marketing of educational services, and this is reinforced by a high value (Beta), explanation variance, which reached (29\%). Based on these results, it rejects the nihilistic hypothesis, and accepts the alternative hypothesis (the study hypothesis) which states that there is a statistically significant effect at the level of significance $(\alpha \leq 0.05)$ of incentives and appreciation in the marketing of educational services.

The fourth sub-hypothesis states that, there is a statistically significant effect at the level of significance $(\alpha \leq 0.05)$ for teams on market educational services.

Table 9

Results of testing the impact of work teams on marketing educational services.

\begin{tabular}{llll}
\hline Beta & $\mathrm{t}$ (value) & $\mathrm{t}$ sig. & $\mathrm{R} 2$ \\
\hline 0.625 & 6.723 & $* 00.00$ & 0.534 \\
\hline * Statisticaly significant at the let
\end{tabular}

* Statistically significant at the level of significance $(\alpha=0.05)$

It is noted from Table 9 that the value of $(t)$ amounted to $(6.723)$ with a probability value $(0,000)$ which is less than the level of significance $(\alpha=0.05)$, which indicates a statistically significant effect of the work teams on the marketing of educational services, and this is enhanced by a high value (Beta), explanation value, which reached (50\%). Based on these results, it rejects the nihilistic hypothesis, and accepts the alternative hypothesis (the hypothesis of the study) which states that there is a statistically significant effect at the level of significance $(\alpha \leq 0.05)$ on teams in marketing educational services.

The fifth sub-hypothesis states that, there is a statistically significant effect at the level of significance ( $\alpha \leq 0.05)$ of workers' participation in decisions on the marketing of educational services.

Table 10

Results of testing the impact of workers' participation in decisions in the marketing on educational services.

\begin{tabular}{lll}
\hline Beta & $\mathrm{t}($ value $)$ & $\mathrm{t}$ sig. \\
\hline 0.615 & 6.402 & $0.000^{*}$
\end{tabular}

* Statistically significant at the level of significance $(\alpha=0.05)$

It is noted from Table 10 that the value of $(\mathrm{t})$ reached (6.402) with a probability value $(0,000)$ which is less than the level of significance $(\alpha=0.05)$, which indicates a statistically significant effect of the participation of workers in decisions in the marketing on educational services, and this is enhanced by a rise Value (Beta), explanation value, which reached (49\%). Based on these results, it rejects the nihilistic hypothesis, and accepts the alternative hypothesis (the study hypothesis) which states that there is a statistically significant effect at the level of significance $(\alpha \leq 0.05)$ for the participation of workers in decisions on the marketing of educational services.

\section{Conclusion}

By analyzing the results of the study, we have found that the Prince Sattam bin Abdulaziz University must take care of its workers and involve them in the decision-making process and work in the spirit of one team and receive their suggestions and recommendations regarding the development of work at the university. Likewise, the higher management of the university should seek to improve and develop the conditions of work in it and work to increase the material and moral incentives provided to workers as well as involve workers in the decision-making process and carry out more marketing studies and poll the opinions of customers outside the university in order to improve the level of educational services provided to them and the local community generally.

\section{References}

Alahmmed, H. (2018). The quality of banking services and their marketing methods. Journal of the Faculty of Economics, 4(3), 523-564.

Al-Hazmia, N. (2020a). A study on the dimensions of the quality of tourism services in the Kingdom of Saudi Arabia. Management Science Letters, 10(5), 1115-1120.

Al-Hazmi, N. (2020b). Internal marketing policies and procedures at Prince Sattam Bin Abdulaziz University and the extent of workers' satisfaction. Management Science Letters, 10(7), 1427-1436.

AL-Hazmi, N \& Alkhateeb, T. (2020). Obstacles to implementing total quality management in Saudi Arabia marketing tourism Services. Management Science Letters, 10(3), 507-514.

Alsaid, S. (2015). Study the marketing of university services in the light of total quality management. Journal of Arab Studies in Education and Psychology, 2(61), 297-374.

Alsaid, M.A. (2018). Marketing of university Services. Business Administration Journal of AlMounofiah University, 2(4), 321-334.

Althamoor, H. (2017). Marketing orientation for higher education institutions in Jordan. The Jordanian Journal of Business Administration, 3(13), 424-445. 
Ghosha, A., \& Takriti, M. (2017). The effect of total quality management on the marketing of banking services. Al-Balqa Applied University Journal, 2(4), 356-496.

Hatto, M., \& Alhaj, R. (2017). The effect of marketing university services on achieving the goals of Shaqra University. Journal of Amarbac, 24(8), 73-86.

Ksem, E. (2018). Convenience of marketing means in universities to attract new students. Palestine University Journal for Research and Studies, 4(8), 94-143.

Retha, M. (2018). The reality of marketing the quality of educational services. The Journal of Administration and Economics, 2(10), 560-573.

Sallis, E. (2014). Total quality management in education. Routledge.

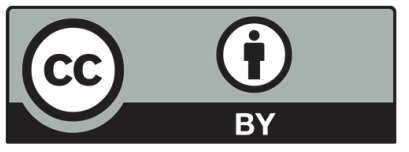

(C) 2020 by the authors; licensee Growing Science, Canada. This is an open access article distributed under the terms and conditions of the Creative Commons Attribution (CC-BY) license (http://creativecommons.org/licenses/by/4.0/). 